\title{
Electricity derivatives and risk management
}

\author{
S.J. Deng ${ }^{\mathrm{a}, *}$, S.S. Oren ${ }^{\mathrm{b}}$ \\ ${ }^{a}$ School of Industrial and Systems Engineering, Georgia Institute of Technology, Atlanta, GA 30332-0205, USA \\ ${ }^{\mathrm{b}}$ Department of Industrial Engineering and Operations Research, University of California, Berkeley, CA 94720, USA
}

\begin{abstract}
Electricity spot prices in the emerging power markets are volatile, a consequence of the unique physical attributes of electricity production and distribution. Uncontrolled exposure to market price risks can lead to devastating consequences for market participants in the restructured electricity industry. Lessons learned from the financial markets suggest that financial derivatives, when well understood and properly utilized, are beneficial to the sharing and controlling of undesired risks through properly structured hedging strategies. We review different types of electricity financial instruments and the general methodology for utilizing and pricing such instruments. In particular, we highlight the roles of these electricity derivatives in mitigating market risks and structuring hedging strategies for generators, load serving entities, and power marketers in various risk management applications. Finally, we conclude by pointing out the existing challenges in current electricity markets for increasing the breadth, liquidity and use of electricity derivatives for achieving economic efficiency.
\end{abstract}

(c) 2005 Elsevier Ltd. All rights reserved.

\section{Introduction}

Electricity spot prices are volatile due to the unique physical attributes of electricity such as nonstorability, uncertain and inelastic demand and a steep supply function. Uncontrolled exposure to market price risks could lead to devastating consequences. During the summer of 1998, wholesale power prices in the Midwest of US surged to a stunning $\$ 7000$ per MWh from the ormal price range of \$30-\$60 per MWh, causing the defaults of two power marketers in the east coast. In February 2004, persistent high prices in Texas during a 3-day ice storm led to the bankruptcy of a retail energy provider that was exposed to spot market prices. And of course, the California electricity crisis of 2000/2001 and its devastating economic consequences are largely attributed to the fact that the major utilities were not properly hedged through long-term supply contracts. Such expensive lessons have raised the awareness

\footnotetext{
* Corresponding author. Tel.: + 1404894 6519; fax: + 14048942301.

E-mail address: deng@isye.gatech.edu (S.J. Deng).
} 
of market participants to the importance and necessity of risk management practices in competitive electricity market.

Hedging of risk by a corporation should in principle be motivated by the goal of maximizing firm's value. Hedging achieves value enhancement by reducing the likelihood of financial distress and its ensuing costs, or by reducing the variance of taxable incomes and its associated present value of future tax liabilities. Regulatory rules also play an important role in hedging practices. In California, for instance, the regulators granted the incumbent investor-owned utilities (IOUs) a fixed time frame to recover their stranded generation costs through the Competition Transition Charge. Fearing adverse market conditions causing insufficient recovery of the stranded costs, one major utility company hired investment bankers to structure and implement an extensive hedging strategy for its stranded-cost recovery. On the other hand, the reluctance of the regulators in California to immunize the IOUs against ex-post prudence review of long-term supply contracts discouraged the adoption of such contracts, resulting in over-reliance of the IOUs on the spot market for electricity procurement. This excessive exposure led to the near collapse of the California utility industry in 2001, with devastating economic losses due to prolonged outages and substantial rate increases.

As the competitive but volatile electricity markets mature, generation companies, power marketers and load serving entities (LSEs) seek certainty in their costs and revenues through hedging practices and contracting and active trading. Such activities involve quantifying, monitoring and controlling trading risks in the wholesale and retail power markets, which in turn require appropriate risk management tools and methodology.

On the supply side, managing risk associated with long-term investment in generation and transmission requires methods and tools for planning under uncertainty and for asset valuation. Much of the demands for generation asset valuation methods were spurred by the mandatory divestiture of generation assets already owned by major utility companies in various jurisdictions. For example, in California, most of the fossil-fuel plants held by the three IOUs, which account for about $60 \%$ of the total installed capacity in California by 2000 , have been or will be divested to other parties. The need for asset valuation also rises from analysis of investment in new generation capacity and from efforts by regulators in the US and abroad to develop incentives for investment in generation capacity to meet supply adequacy and system reliability objectives.

A fundamental vision underlying the worldwide movement toward a competitive electricity industry has been that most of the efficiency gains from restructuring come from long-run investments in generating capacity. Under the state-ownership or required rate-of-return regulatory regime, utility companies were allowed to earn a regulated rate of return above their cost of capital. Once regulators approved the construction costs of a power generating plant, the costs would be passed onto consumers through regulated electricity prices over the life of the investment, independent of the fluctuation in market value of the investment over time due to changing energy prices, improving technology, and evolving supply and demand conditions. Most of the investment risks in generating capacity were allocated to consumers rather than producers. Firms, therefore, had little incentives to avoid excessive cost of investment and they focused on improving and maintaining quality of service rather than on developing and adopting new generation technology.

Electricity market reforms around the world have shifted much of the investment risk from consumers to producers. Under the ideal theoretical paradigm, shareholders bear all the investment risk and consumers bear the price risk, with competitive entry pushing generation capacity toward desired longterm equilibrium. In such an ideal market environment, suppliers and consumers are free to choose their 
desired level of risk exposure, achieved through voluntary risk management practices. Unfortunately, this idealized vision of a competitive electricity market is not working as expected, primarily due to such market imperfections as lack of demand response, abuse of locational market power, and political resistance to high prices reflecting scarcity rents and shortages.

With few exceptions such as Australia (where electricity spot prices are allowed to rise to $\$ 10,000$ per $\mathrm{MWh}$ ), most restructured electricity markets in the US and around the world have backed away from the idealized economic market models and instituted price caps and various capacity payment mechanisms. Such regulatory interventions allocate risks between consumers and producers by limiting price volatility for consumers and assuring investment cost recovery for generators. From a risk management perspective, these intervention schemes are mandatory backstop hedging that limits the exposures of consumers and producers. The proper design of such schemes requires the same pricing and asset valuation tools as voluntary risk management practices in a competitive market. For instance, a price cap of $\$ 1000 / \mathrm{MWh}$ can be viewed as a mandatory call option imposed on all produced electricity with a strike price of $\$ 1000 / \mathrm{MWh}$, with the option premium being the proper capacity payment for generators abiding by the cap.

The organization of the rest of the paper is as follows. Section 2 describes the institutional features of several types of commonly traded electricity instruments. Section 3 highlights the essential elements in electricity derivative pricing and introduces the pricing methodologies. Section 4 illustrates the roles of these electricity instruments in risk management applications. Section 5 concludes.

\section{Different types of electricity financial and physical instruments}

This section reviews various electricity financial/physical instruments traded on the exchanges and over the counters. Most of the electricity futures and options on futures are traded on the New York Mercantile Exchange (NYMEX) [1]. However, the trading volume of electricity futures is less than electricity forwards traded in the over-the-counter (OTC) markets. A large variety of electricity derivatives are traded among market participants in the OTC markets, including forward contracts, swaps, plain vanilla options, and exotic (i.e. non-standard) options like spark spread options, swing options and swaptions [2-6]. Other important trading vehicles for hedging the price risk of long-term revenue streams and service obligations are termed as structured transactions, including tolling agreements [7,8] and load-serving full requirement contracts. The institutional details of these instruments are given below.

\subsection{Electricity forwards, futures and swaps}

The plainest forms of electricity derivatives are forwards, futures and swaps. Being traded either on the exchanges or over the counters, these power contracts play the primary roles in offering future price discovery and price certainty to generators and LSEs.

\subsubsection{Electricity forwards}

Electricity forward contracts represent the obligation to buy or sell a fixed amount of electricity at a pre-specified contract price, known as the forward price, at certain time in the future (called maturity or expiration time). In other words, electricity forwards are custom-tailored supply contracts between 
a buyer and a seller, where the buyer is obligated to take power and the seller is obligated to supply. The payoff of a forward contract promising to deliver one unit of electricity at price $F$ at a future time $T$ is

$$
\text { Payoff of a Forward Contract }=\left(S_{T}-F\right)
$$

where $S_{T}$ is the electricity spot price at time $T$. Although the payoff function (1) appears to be the same as for any financial forwards, electricity forwards differ from other financial and commodity forward contracts in that the underlying electricity is a different commodity at different times. The settlement price $S_{T}$ is usually calculated based on the average price of electricity over the delivery period at the maturity time $T$.

Consider a forward contract for the on-peak electricity on day $T$. 'On-peak electricity' refers to the electricity delivered over the daily peak-period, traditionally defined by the industry as 06:00-22:00. The daily 'off-peak' period is the remaining hours of the day. In this case, $S_{T}$ is obtained by averaging the 16 hourly prices from 06:00 to 22:00 on day $T$.

Based on the delivery period during a day, electricity forwards can be categorized as forwards on on-peak electricity, off-peak electricity, or 'around-the-clock' (24 h per day) electricity. As almost all electricity derivatives have such categorization based on the delivery time of a day, we will not repeat this point.

Generators such as independent power producers (IPPs) are the natural sellers (or, short-side) of electricity forwards while LSEs such as utility companies often appear as the buyers (or, long-side). The maturity of an electricity forward contract ranges from hours to years although contracts with maturity beyond two years are not liquidly traded. Some electricity forwards are purely financial contracts, which are settled through financial payments based on certain market price index at maturity, while the rest are physical contracts as they are settled through physical delivery of underlying electricity. Examples of financially settled electricity forwards include the Contract for Differences in the United Kingdom and Australian power markets.

Electricity forwards with short maturity like $1 \mathrm{~h}$ or 1 day are often physical contracts, traded in the physical electricity markets such as the Pennsylvania-New Jersey-Maryland (PJM) power pool market and the energy balancing market operated by the California Independent System Operator (CAISO) in US. Those with maturity of weeks or months can be either physical contracts or financial contracts and they are mostly traded through brokers or directly among market participants (namely, traded in the OTC markets).

Electricity forward contracts are the primary instruments used in electricity price risk management. LSEs (e.g. local distribution companies) typically combine several months of forward/futures contracts to form a close match to the long-term load shape of their customers. Other power marketers usually use forwards to hedge their positions in electricity options and other complex electricity derivatives.

\subsubsection{Electricity futures}

First traded on the NYMEX in March 1996, electricity futures contracts have the same payoff structure as electricity forwards. However, electricity futures contracts, like other financial futures contracts, are highly standardized in contract specifications, trading locations, transaction requirements, and settlement procedures. The most notable difference between the specifications of electricity futures and those of forwards is the quantity of power to be delivered. The delivery quantity specified in electricity futures contracts is often significantly smaller than that in forward contracts. 
For example, a Mid-Columbia electricity futures traded on the NYMEX specifies a delivery quantity of $432 \mathrm{MWh}$ of firm electricity, delivered to the Mid-Columbia hub at a rate of $1 \mathrm{MW}$ per hour, 16 on-peak hours per day during delivery month, while a corresponding forward contract has a delivery rate of $25 \mathrm{MW}$ per hour for the same delivery periods in a month.

Electricity futures are exclusively traded on the organized exchanges, while electricity forwards are usually traded over-the-counter in the form of bilateral transactions. This fact makes the futures prices more reflective of higher market consensus and transparency than the forward prices. The majority of electricity futures contracts are settled by financial payments rather than physical delivery, which lower the transaction costs. In addition, credit risks and monitoring costs in trading futures are much lower than those in trading forwards, since exchanges implement strict margin requirements to ensure financial performance of all trading parties. The OTC transactions are vulnerable to financial non-performance due to counterparty defaults. The fact that the gains and losses of electricity futures are paid out daily, as opposed to being cumulated and paid out in a lump sum at maturity time, as in trading forwards, also reduces the credit risks in futures trading.

In summary, as compared to electricity forwards, the advantages of electricity futures lie in market consensus, price transparency, trading liquidity, and reduced transaction and monitoring costs while the limitations stem from the various basis risks associated with the rigidity in futures specification and the limited transaction quantities specified in the contracts.

\subsubsection{Electricity swap}

Electricity swaps are financial contracts that enable their holders to pay a fixed price for underlying electricity, regardless of the floating electricity price, or vice versa, over the contracted time period. They are typically established for a fixed quantity of power referenced to a variable spot price at either a generator's or a consumer's location. Electricity swaps are widely used in providing short- to mediumterm price certainty up to a couple of years. They can be viewed as a strip of electricity forwards with multiple settlement dates and identical forward price for each settlement.

Electricity locational basis swaps are also commonly used to lock in a fixed price at a geographic location that is different from the delivery point of a futures contract. That is, a holder of an electricity locational basis swap agrees to either pay or receive the difference between a specified futures contract price and another locational spot price of interest for a fixed constant cash flow at the time of the transaction. These swaps are effective financial instruments for hedging the basis risk on the price difference between power prices at two different physical locations.

\subsection{Electricity options}

The power industry had been utilizing the idea of options through embedded terms and conditions in various supply and purchase contracts for decades, without explicitly recognizing and valuing the options until the beginning of the electricity industry restructuring in UK, US and the Nordic countries in the 1990s. The emergence of the electricity wholesale markets and the dissemination of option pricing and risk management techniques have created electricity options not only based on the underlying price attribute (as in the case with plain vanilla electricity call and put options), but also other attributes like volume, delivery location and timing, quality, and fuel type.

Basically, a counterpart of each financial option can be created in the domain of electricity options by replacing the underlying of a financial option with electricity (see [9] for introduction to various kinds of 
financial options). Here, we describe a sample of electricity options that are commonly utilized in risk management applications in generation and distribution sectors. These options usually have short- to medium maturity times such as months or a couple of years. Options with maturity times longer than 3 years are usually embedded in long-term supply or purchase contracts, which are termed as structured transactions.

\subsubsection{Plain call and put options}

Electricity call and put options offer their purchasers the right, but not the obligation, to buy or sell a fixed amount of underlying electricity at a pre-specified strike price by the option expiration time. They have similar payoff structures as those of regular call and put options on financial securities and other commodities. The payoff of an electricity call option is

$$
\text { Payoff of an electricity call option }=\max \left(S_{T}-K, 0\right)
$$

where $S_{T}$ is the electricity spot price at time $T$ and $K$ is the strike price.

The underlying of electricity call and put options can be exchange-traded electricity futures or physical electricity delivered at major power transmission inter-ties, like the ones located at CaliforniaOregon Border and Palo Verde in the Western US power grid. The majority of the transactions for electricity call and put options occur in the OTC markets. Electricity call and put options are the most effective tools available to merchant power plants and power marketers for hedging price risk because electricity generation capacities can be essentially viewed as call options on electricity, particularly when generation costs are fixed.

\subsubsection{Spark spread options}

An important class of non-standard electricity options is the spark spread option (or, spark spread). Spark spreads are cross-commodity options paying out the difference between the price of electricity sold by generators and the price of the fuels used to generate it. The amount of fuel that a generation asset requires to produce one unit of electricity depends on the asset's fuel efficiency or heat rate (Btu/kWh). The holder of a European- spark spread call option written on fuel $G$ at a fixed heat rate $K_{\mathrm{H}}$ has the right, but not the obligation, to pay at the option's maturity $K_{\mathrm{H}}$ times the fuel price at maturity time $T$ and receive the price of one unit of electricity. Thus, the payoff at maturity time $T$ is

$$
\text { Payoff of a spark spread call }=\max \left(S_{T}-K_{\mathrm{H}} \times G_{T}, 0\right)
$$

where $S_{T}$ and $G_{T}$ are the electricity and fuel prices at time $T$, respectively.

Abstracting away the operational characteristics of a fossil fueled power generator (e.g. startup cost and ramping constraints), the per $\mathrm{kW}$ benefit of owning the right to use the generator is equivalent to having $1 \mathrm{~kW}$ spark spread call option with a strike heat rate matching the generator's operating heat rate. Based on this observation, it is clear that spark spread call options play important roles in hedging the price risk of the output electricity of fossil fueled power plants and further serve as key instruments in valuing those generation assets [10,11].

\subsubsection{Callable and putable forwards}

Two interesting types of electricity derivatives termed as callable forward and putable forward are introduced in Refs. $[12,13]$ to mimic the interruptible supply contracts and the dispatchable independent 
power producer contracts. In a callable forward contract, the purchaser of the contract longs one forward contract and shorts one call option with a purchaser-selected strike price. The seller of the forward contract holds opposite positions and can exercise the call option if the electricity price exceeds the strike price, effectively canceling the forward contract at the time of delivery. The purchaser gets an 'interruptibility' discount on the forward price, which is equal to the option premium at the time of contracting continuously compounded to the delivery time.

In a putable forward, the purchaser longs one forward contract and one put option with a sellerselected strike price. The seller holds the corresponding short positions. The purchaser exercises the put option if the electricity price drops below the strike price at the maturity time, effectively canceling the forward contract. At the time of contracting, the purchaser needs to pay a 'capacity availability' premium over the forward energy price, which equals the put option price at that time, continuously compounded to the maturity time.

One variation of the callable forwards is proposed by adding an earlier notification date for exercising the call option in a callable forward before the contract matures $[14,15]$. This emulates an interruptible service contract with early notification [16].

\subsubsection{Swing options}

Electricity swing options are adopted from their well-known counterparts in the natural gas industry [5]. Also known as flexible nomination options, swing options have the following defining features. First, these options may be exercised daily or up to a limited number of days during the period in which exercise is allowed. Second, when exercising a swing option, the daily quantity may vary (or, swing) between a minimum daily volume and a maximum volume. However, the total quantity taken during a time period such as a week or a month needs to be within certain minimum and maximum volume levels. Third, the strike price of a swing option may be either fixed throughout its life or set at the beginning of each time period based on some pre-specified formula. Last, if the minimum-take quantity of any contract period is missed by the buyer, then a lump sum penalty or a payment making up the seller's revenue shortfall needs to be paid (i.e. take-or-pay).

\subsection{Structured transactions}

Structured bilateral transactions are powerful tools for power market participants to share and control a variety of risks including price and quantity risks over a potentially long time horizon.

\subsubsection{Tolling contracts}

Tolling is one of the most innovative structured transactions embraced by the power industry. A tolling agreement is similar to a common electricity supply contract signed between a buyer (e.g. a power marketer) and an owner of a power plant (e.g. an IPP) but with notable differences. For an upfront premium paid to the plant owner, it gives the buyer the right to either operate and control the scheduling the power plant with the ISO or simply take the output electricity during pre-specified time periods subject to certain constraints. In addition to inherent operational constraints of the underlying power plant, there are often other contractual limitations in the contract on how the buyer may operate the power plant or take the output electricity. For instance, a tolling contract almost always has a clause on the maximum allowable number of power plant restarts. These constraints make the pricing of tolling contracts a very challenging task. The analogy between holding a tolling contract and owning 
the underlying merchant power plant, however, leads to a numerical approach for valuing and hedging tolling contracts [7]. Alternatively, one may use a statistical approach for benchmarking the price reasonableness of tolling contracts based on historical electricity price and fuel costs [8].

\subsubsection{Load-serving full-requirement contracts}

Most large electricity consumers prefer a power supply contract with flexible consumption terms. Specifically, they desire to pay a fixed rate per unit of energy for the actual consumption quantity, regardless of the quantity being high or low. Such a contract is termed as a load-serving full-requirement contract.

Suppose an electricity supplier (or, LSE) signs a full-requirement contract with a customer and then utilizes futures contracts to lock in a fixed quantity of electricity supply at a fixed cost for hedging the expected energy consumption of the customer [17,18]. The LSE is then at the risk of either under- or over-hedging, as the consumption quantity of the customer will almost surely deviate from the amount hedged by the futures contracts. When the electricity spot price is high (low), the total demand for electricity is likely to be high (low) as well. A case in point is the periods of unusual cooling/heating needs. Hence, if the market price of electricity is higher than the fixed contract rate for serving electricity, chances are that the customer's energy consumption level is significantly higher than the hedged quantity. As a result, the LSE is under-hedged relative to its load obligation and must purchase electricity in the open market to serve its customer at a loss because the wholesale spot price most likely exceeds the contracted price paid by consumers. Conversely, when the electricity spot price is low, the LSE faces the risk of being over-hedged and having to sell the surplus in the spot market or settle it financially at a price below its long-term contract price.

The above illustrates the under- and over-hedging exposures faced by an LSE due to the volumetric uncertainty in customers' load and the positive price-load correlation. To hedge the volumetric risk, the LSE would need to buy an electricity option on the consumption quantity of its customers. Unfortunately, such an option is usually unavailable in the marketplace. Although perfect hedging may not be possible, weather derivatives $[19,20]$ that exploit the correlation between load and temperature can be used. Section 4.4 describes another approach based on an optimal hedging portfolio of standard derivatives that exploits the positive correlation between power prices and consumption quantity [21].

\subsection{Financial derivatives on electricity transmission capacity}

Open access to, efficient utilization of, and adequate investment in transmission networks are critical for the electricity wholesale markets and retail competitions to be workable and efficient. Intuitively, rights are required for using transmission networks and rules are needed for rationing transmission usage when networks become congested. There are two major proposals for using financial instruments as transmission rights in US: (a) the point-to-point financial transmission rights (FTRs) [22-24]; and (b) the flowgate rights (FGRs) [25,26], as outlined in the Standard Market Design (SMD) put forth by the Federal Energy Regulatory Commission (FERC). FTRs and FGRs are electricity derivatives, with their values derived from the network transmission capacity.

\subsubsection{FTR and FTR options}

In an electricity market such as the PJM that employs locational market price (LMP), a point-topoint FTR is specified over any two locations in the power transmission grid. An FTR entitles its 
holder to receive compensation (or pay) for transmission congestion charges that arise when the grid is congested. The congestion charge/payment (or, payoff) associated with one unit of FTR is equal to the difference between the two locational prices of one unit of electricity resulting from the re-dispatch of generators out of merit order to relieve transmission congestion. The primary markets for the FTR trading are auctions held by the independent system operators (ISOs) of power markets.

An FTR option offers the right to the FTR settlement without the obligation to pay when that settlement is negative. Hence, the settlement of an FTR option equals to the positive part of the corresponding two-sided point-to-point FTR.

\subsubsection{FGRs}

Flowgates are defined over all transmission elements such as lines, transformers, or linear combinations of them. Each transmission element has two elemental flowgates, one in each direction. An elemental flowgate has a rated capacity in megawatts in its pre-specified direction corresponding to the capacity of an underlying transmission element. Thus, flowgate rights are link-based transmission rights for hedging transmission risks. The values of flowgate rights can be established through auctions conducted by the ISOs. The spot price upon which the settlement of flowgate rights is based is given by the real time shadow price on the corresponding constrained element, determined by the security constrained economic dispatch algorithm employed by an ISO. Since these shadow prices are nonnegative, FGRs are inherently defined as options.

\section{Pricing electricity derivatives}

Since the value of electricity derivatives are based on the underlying electricity prices, modeling electricity price is the most critical component in pricing electricity derivatives. Due to the unique physical and operational characteristics of electricity production and transmission processes, electricity price exhibits different behaviors than other financial prices which can be often described by Geometric Brownian Motion. There has been a growing literature addressing mainly two competing approaches to the problem of modeling electricity price processes:

(a) 'Fundamental approach' that relies on simulation of system and market operation to arrive at market prices; and

(b) 'Technical approach' that attempts to model directly the stochastic behavior of market prices from historical data and statistical analysis.

While the first approach provides more realistic system and transmission network modeling under specific scenarios, it is computationally prohibitive due to the large number of scenarios that must be considered. Such analysis may be necessary for pricing financial transmission rights (in particular, flowgate rights) but not for the other electricity derivatives. Therefore, we shall focus our attentions on the second approach and review the corresponding methodologies for pricing electricity derivatives.

Approaches to characterize market prices include discrete-time time series models such as GARCH and its variants [27-32], Markov regime-switching models [33], continuous-time diffusion models such 
as mean-reversion [11,34,35], jump-diffusion [2,3,36], and other diffusion models [37,38]. There are also models proposed for direct modeling of electricity forward curves [39,40].

While a straightforward application of the maximum likelihood estimation (MLE) method yields the parameter estimates of a discrete-time time series model, it does not yield analytic expressions for derivative prices. In fact, Monte Carlo simulation and lattice-based approaches are the only feasible derivative pricing methods under time-series price models. For continuous-time diffusion models, model parameters can be estimated by applying moment-based methods, such as the generalized method of moments, which may not be as efficient as the MLE method. Nonetheless, more option pricing methods (e.g. the analytic solution approach and the partial differential equation (PDE) approach) become applicable under the diffusion price models.

Deng [3] was the first to employ a multifactor affine jump diffusion (AJD) processes to model electricity spot prices under several specifications, including regime switching and stochastic volatility. Under the assumption that electricity prices follow AJD processes, an extended Fourier transform technique developed in Ref. [41] can be applied to derive analytic expressions (up to Fourier inversion) for a variety of derivative prices. Specifically, prices of forwards, calls/puts and spark spreads were derived in Ref. [3] under three different electricity price models, and prices of callable forwards with an early notification were obtained in Ref. [14].

When there is a large set of market data available, the most appropriate approach to pricing electricity options is to infer the risk-neutral distribution of the underlying electricity price from the market data and then obtain the prices of the electricity derivatives based on the premise of noarbitrage. If there is not enough forward-looking market information for implementing a noarbitrage pricing model, then equilibrium models can be applied to obtain derivative prices, as in Refs. [31,34,40,42,43] for forward prices and [44] for spark spreads. In certain cases, statistical benchmark analysis based on historical data can provide a sense of the reasonableness on the electricity options prices [8].

The binomial/multinomial lattice and Monte Carlo simulation methods are powerful numerical tools for pricing electricity options with complex structures and/or under a complicated model for the electricity price process. For instance, given the complex structure of a swing option or a tolling contract, it is impossible to obtain prices of such contracts either in closed-forms or through PDEs. Thus, swing options are priced by lattice models $[45,46]$, or by approximation methods for obtaining price lower bounds [47]. The pricing of tolling contracts requires a combination of Monte Carlo simulation with dynamic programming [7].

\section{Risk management applications}

\subsection{Hedging a generator's output}

Albeit having simple payoff structures, forwards, swaps, and call options are effective tools for a generator with fixed per unit cost to lock in profits by selling forwards, fixed-price swaps, and call options on electricity. When the forward/swap rate or the strike price of the call options is higher than the fixed cost, the generator's profits are guaranteed.

However, if the generating costs are market-based (e.g. a natural gas fired merchant power plant that burns natural gas at market price), the selling forwards, swaps and calls will expose 
the generator to potential fuel cost increases. In such a case, a properly constructed portfolio of spark spread calls would be the right tool for hedging a generator's revenue stream over a given time period.

The operational efficiency of a natural gas fired power plant is characterized by its operating heat rate. Therefore, the financial benefit of owning a portfolio of spark spread calls with strike heat rates identical to the operating heat rate of the plant is the same as owning the power plant during the time period of the options' maturity times. This observation leads to the valuation and hedging method for generation capacity proposed in Refs. [10,11]. When taking into account the operational characteristics, latticebased method [48] and simulation method [35] are necessary to determine pricing and hedging strategies of generation capacity.

In the case, where the electricity forward market at the generator's location is not liquidly traded, electricity forwards from adjacent trading hubs or even forwards on the input fuel, which are liquidly traded, can be utilized to cross-hedge the electricity output price $[49,50]$.

\subsection{Ensuring generation adequacy}

Oren [51,52] and Chao and Wilson [53] propose a new role for options with long maturity to address the resource adequacy problem. They propose a scheme for ensuring generation adequacy via call options as obligations imposed on the LSEs. Call options provide an attractive alternative to artificial capacity products such as installed capacity (ICAP) employed in New York, New England, and PJM, whose demand is based only on administrative requirements and which have no intrinsic value. By requiring LSEs to purchase a proper portfolio of options, a regulator can achieve spot price volatility reduction by implementing price insurance while using the premium to stabilize generators' income and enhance investment incentives.

\subsection{Callable forwards and interruptible service contracts}

The restructured electricity markets have shown little demand response to price spikes. The enormous price volatility affirms the need for demand responsiveness to make these markets workable. As load curtailment can provide an efficient substitute for generation capacity in meeting balancing energy and reserves needs, flexible loads are viable and valuable resources in taming price volatility.

Consider the traditional utility interruptible service contracts utilized in demand-side management (DSM) to mitigate supply shortages. These interruptible contracts are readily implementable through standard electricity derivatives [12-14]. For instance, a synthetic interruptible service contract offered by an LSE is a callable forward under which the LSE sells a forward to and buys a call option from its customer. Furthermore, with a liquid electricity derivative market, the discounts offered to the interrupted services would be set through market trading instead of bilateral negotiations thus making the pricing of the interruptible services more transparent and efficient.

\subsection{Hedging congestion risk of bilateral transactions}

From the perspective of new power network transmission users, FTRs can be viewed as an instrument for hedging their exposure to congestion cost risk. A 1-MW bilateral transaction between two points in a transmission network is charged (or credited) the nodal price difference between 
the point of withdrawal and the point of injection. At the same time (assuming that transmission rights are fully funded), a 1 MW FTR between two points is an entitlement (or obligation) for the difference between the nodal prices at the withdrawal node and the injection node. Thus regardless of how the system is dispatched, a $1 \mathrm{MW}$ FTR between two nodes is a perfect hedge against the uncertain congestion charge between the same two nodes.

The hedging properties of FTRs make them ideal instruments for converting historical entitlements to firm transmission capacity into tradable entitlements that hold the owners of such entitlements harmless, while enabling them to cash out when someone else can make more efficient use of the transmission capacity covered by these entitlements. In other words, FTRs make it relatively easy to preserve the status quo while opening up the transmission system to new and more efficient use. A word of caution is that the hedging function of FTRs may not be perfect due to changing network operating conditions and potential inherent trading inefficiency [54]. Some ISOs derate FTR settlements in order to cover congestion revenue shortfalls due to transmission contingencies not accounted for in the FTR auction. In such cases, depending on the derating approach, FTRs may not provide perfect hedges either.

\subsection{Hedging volumetric risks}

LSEs providing electricity service at regulated prices in restructured electricity markets are wary of both price and quantity risks [17,18]. As the electricity markets are inherently incomplete, the quantity risk cannot be perfectly hedged. Commonly proposed hedging alternatives include the implementation of a minimal variance hedge through purchasing electricity forwards [18] and the utilization of weather derivatives.

Recent work reported in Ref. [21] addresses the problem of hedging volumetric risks by risk-averse LSEs, whose hedging objective is to maximize a concave utility function. Exploiting the correlation between consumption quantities and spot prices, the authors developed an optimal, zero-cost hedging function described by a payoff function of spot price. They also demonstrate how such a hedging strategy can be implemented through a portfolio of standard forwards and a spectrum of call and put options with various strike prices.

\section{Conclusion}

In electricity market restructuring, electricity derivatives play an important role in establishing price signals, providing price discovery, facilitating effective risk management, inducing capacity investments in generation and transmission, and enabling capital formation. Custom design of electricity financial instruments and structured transactions can provide energy price certainty, hedge volumetric risk, synthesize generation and transmission capacity, and implement interruptible service contracts.

Admittedly, many exotic forms of electricity options can meet specific needs for hedging and speculation. However, we emphasize the importance of standardization. Future research should focus on identifying standardized electricity derivatives and utilization of financial engineering tools to synthesize and replicate alternative contracts using standardized instruments. Such standardization will reduce transaction costs and produce liquidity, which in turn will improve the efficiency of risk management practices. 


\section{Acknowledgements}

This research is supported in part by the NSF Grant ECS-0134210 (Deng), National Science Foundation Grant ECS-0224779 (Oren) and a Power System Engineering Research Center (PSERC) grant (Deng and Oren).

\section{References}

[1] Johnson B, Sogomonian A. Electricity futures. The US power market. London: Risk Publications; 1997 p. $83-98$.

[2] Clewlow L, Strickland C. Energy derivatives: pricing and risk management. London: Lacima Publications; 2000.

[3] Deng SJ. Stochastic models of energy commodity prices and their applications: mean-reversion with jumps and spikes. POWER working paper, University of California Energy Institute, Berkeley; 1999.

[4] Eydeland A, Wolyniec K. Energy and power risk management. Chichester: Wiley; 2003.

[5] Kaminski V. The challenge of pricing and risk managing electricity derivatives. The US power market. London: Risk publications; 1997.

[6] Pilipovic D. Energy risk: valuing and managing energy derivatives. New York: McGraw-Hill; 1998.

[7] Deng SJ, Xia ZD. Pricing and hedging power supply contracts: the case with tolling agreements. Working paper, Georgia Institute of Technology; 2003.

[8] Woo CK, Olson A, Orans R. Benchmarking the price reasonableness of an electricity tolling agreement. Electricity J 2004; 17(5):65-75.

[9] Hull J. Options, futures, and other derivative. 4th ed. Englewood, NJ: Prentice-Hall; 2000.

[10] Deng SJ. Valuation of investment and the opportunity to invest in power generation assets with spikes in power prices. Manage Financ 2005;31(6):95-115.

[11] Deng SJ, Johnson B, Sogomonian A. Exotic electricity options and the valuation of electricity generation and transmission assets. Decis Support Syst 2001;30(3):383-92.

[12] Gedra TW. Optional forward contracts for electric power service contracts. PhD Thesis, University of California, Berkeley; 1991.

[13] Gedra TW, Pravin PV. Markets and pricing for interruptible electric power transactions. IEEE Trans Power Syst 1992;92 [WM 169-3 PWRS].

[14] Kamat R, Oren SS. Exotic options for interruptible electricity supply contracts. Oper Res 2002;50(5):835-50.

[15] Oren SS. Integrating real and financial options in demand-side electricity contracts. Decis Support Syst 2001;V30:279-88.

[16] Strauss TP, Oren SS. Priority pricing of interruptible electric power with an early notification option. Energy J 1993;14(2): 175-95.

[17] Alexander BR. Managing default service to provide consumer benefits in restructured states: avoiding short-term price volatility. Butte, Montana: National Center for Appropriate Technology; 2003.

[18] Woo CK, Karimov R, Horowitz I. Managing electricity procurement cost and risk by a local distribution company. Energy Policy 2004;32(5):635-45.

[19] Cao M, Wei J. Pricing the weather. Risk Mag 2000;67-70.

[20] Pirrong C, Jermakyan M. The price of power: The valuation of power and weather derivatives. Working paper, Oklahoma State University; 2001.

[21] Oum Y, Deng SJ, Oren SS. Volumetric hedging in electricity procurement. Working paper, UC Berkeley; October 2004.

[22] Harvey SM, Hogan WW, Pope SL. Transmission capacity reservations and transmission congestion contracts. Cambridge, MA: John F. Kennedy School of Government, Harvard University; 1997.

[23] Hogan WW. Contract networks for electric power transmission. J Regul Econ 1992;4:211-42.

[24] Hogan WW. Financial transmission right formulations. Cambridge, MA: Center for Business and Government, John F. Kennedy School of Government, Harvard University; 2002.

[25] Chao H-P, Peck S. A market mechanism for electric power transmission. J Regul Econ 1996;10(1):25-60.

[26] Chao H-P, Peck S, Oren SS, Wilson R. Flow-based transmission rights and congestion management. Electricity J 2000; 13(8):38-58. 
[27] Bunn DW, editor. Modelling prices in competitive electricity markets. Chichester: Wiley; 2004.

[28] Duffie D, Gray S. Volatility in energy prices. Manage energy price risk. 2nd ed. London: Risk Publications; 1998.

[29] Goto M, Karolyi GA. Understanding electricity price volatility within and across markets. Working paper, Ohio State University; 2003.

[30] Knittel C, Roberts M. An empirical examination of deregulated electricity prices. Working paper, University of California Energy Institute; 2001.

[31] Longstaff FA, Wang AW. Electricity forward prices: a high-frequency empirical analysis. J Finance 2004;59(4): 1877-900.

[32] Worthington AC, Kay-Spratley A, Higgs H. Transmission of prices and price volatility in Australian electricity spot markets: a multivariate GARCH analysis. Energy Econ 2003.

[33] Mount T, Ethier R. Estimating the volatility of spot prices in restructured electricity markets and the implications for option values. PSerc Working paper, Cornell University; 1998.

[34] Lucia JJ, Schwartz ES. Electricity prices and power derivatives: evidence from the Nordic power exchange. Rev Deriv Res 2002;5(1):5-50.

[35] Tseng CL, Barz G. Short-term generation asset valuation: a real options approach. Oper Res 2002;50(2):297-310.

[36] Barz G, Johnson B. Modeling the prices of commodities that are costly to store: the case of electricity. Proceedings of the Chicago Risk Management Conference, Chicago, IL 1998.

[37] Barlow M. A diffusion model for electricity prices. Math Finance 2002;12(4):287-98.

[38] Deng SJ, Jiang WJ. Levy process driven mean-reverting electricity price model: a marginal distribution analysis. Working paper, Georgia Institute of Technology; 2002.

[39] Audet N, Heiskanen P, Keppo J, Vehvilainen I. Moleling electricity forward curve dynamics in the Nordic market. Working paper, University of Michigan; 2003.

[40] Bjork T, Landen, C. On the term structure of futures and forward prices. SSE/EFI working paper series in economics and finance no. 417; 2000.

[41] Duffie D, Pan J, Singleton K. Transform analysis and asset pricing for affine jump-diffusion. Econometrica 2000;68: 1343-76.

[42] Bessembinder H, Lemmon ML. Equilibrium pricing and optimal hedging in electricity forward markets. J Finance 2002; 57:1347-82.

[43] Kellerhals BP. Pricing electricity forwards under stochastic volatility. Working paper, POWER, Department of Finance, College of Economics and Business Administration, Eberhard Karls University, Tubingen; 2001.

[44] Routledge B, Seppi D, Spatt CS. Equilibrium forward curves for commodities. J Finance 2000;55:1297-338.

[45] Jaillet P, Ronn E, Tompaidis S. Valuation commodity based swing options. Working paper, University of Texas, Austin; 2001.

[46] Thompson AC. Valuation of path-dependent contingent claims with multiple exercise decisions over time: the case of take-or-pay. J Financial Quant Anal 1995;30:271-93.

[47] Keppo J. Pricing of electricity swing options. Preprint, University of Michigan 2002.

[48] Deng SJ, Oren SS. Incorporating operational characteristics and startup costs in option-based valuation of power generation capacity. Probab Eng Inform Sci 2003;17(2):155-81.

[49] Emery G, Liu QW. An analysis of the relationship between electricity and natural gas futures prices. J Futures Markets 2002;22(2):95-122.

[50] Woo CK, Horowitz I, Hoang K. Cross hedging and forward-contract pricing of electricity. Energy Econ 2001;23:1-15.

[51] Oren SS. Capacity payments and generation adequacy in competitive electricity markets. Proceedings of SEPOPE IIV conference, Curitiba, Brazil, May 2000;22-6.

[52] Oren SS. Ensuring generation adequacy in competitive electricity markets. In press, University of Chicago Press.

[53] Chao H-P, Wilson R. Resource adequacy and market power mitigation via option contracts. Proceeding of the POWER Conference, University of California Energy Institute, Berkeley, CA 2004.

[54] Deng SJ, Meliopoulos SA, Oren SS. The inherent inefficiency of simultaneously feasible financial transmission rights auctions. Working paper, Georgia Institute of Technology; 2004. 